The Lindop committee addressed the same broad questions covered by the draft directive, but the two other groups concentrated on medical confidentiality. Despite differences of approach they agreed that neither of the alternative fundamental viewpoints should or could be maintained at the total expense of the other. Total medical secrecy was not an absolute right of the patient or the doctor or appropriate in every circumstance, and medical records had legitimate extended uses. The two reports, however, differed in operational terms. The Black committee stated that medical records should be kept secret except when predefined and agreed conditions were valid - and it listed several pages of them. By contrast, the report of the European Community advisory group positively identified the range of purposes for which medical records could legitimately be used and then defined procedural restrictions on access.

The advisory group based its preference for formulating an operational code of practice on three main considerations. Firstly, a code declares a positive ethical duty to use medical records for the benefit of the whole population. Secondly (like the "Highway Code") it delineates a set of standards and conventions to which legislation can refer, while avoiding the impossible task of devising formal and probably harmful rules for every eventuality. Thirdly, a code with legal back up can be used to control secondary dissemination beyond the stage of the initial breach of secrecy-an essential reassurance if doctors are to be persuaded to release information for the benefit of others. The advisory group reached its conclusions after analysing hindrances to research that had already been encountered in different countries under different administrative and legal systems.

All of this is now forgotten, and there is no evidence that the present cycle in any way builds on the last one. The Monitor's anxieties should therefore be taken seriously. The directive has the marks of an incompetent and ultimately harmful operation. It exudes more than a whiff of legal pedantry, as deadly as the hazards that epidemiologists will no longer be able to investigate or public health practitioners seek to avert. It may be some time before its ill effects are felt, and we may never be permitted to know what they were; but the lives lost will be lives lost, and they are at hazard now.

Professor of Public Health and Epidemiology,

University of Birmingham Medical School,

Birmingham B15 2TT

1 Biomedical and health research in the European Community. Luxembourg: Commission of the European Communities, Directorate XII-F-6, Medical Research Division, 1991. (Newsletter No 3/91.)

\section{The Epidemiology Monitor 1991 Oct; vol 12 (No 8).}

3 Knox EG. The confidentiality of medical records: the principles and practice of protection in a research dependent environment. Luxemburg: Commission of the European Communities, 1984. (Report of working party of Advisory Panel for Social Medicine and Epidemiology in European Economic Community.)

4 Committee on Data Protection. Report. London: HMSO, 1978. (Cmnd 7341.) (Chairman Sir Norman Lindop.)

5 Steering Group on Health Services Information. The protection and maintenance of confidentiality of patient and employee data. London: HMSO, 1984.

\title{
A team future for general practice
}

\section{The end of the one man band}

A remarkable $70 \%$ of the 36000 general practitioners in the United Kingdom have responded to the questionnaire on the future of general practice sent out by the General Medical Services Committee. ${ }^{12}$ The GMSC undertook this survey because it was worried after general practitioners rejected the new contract introduced in 1990 that it was losing touch with the rank and file. In addition, the committee wanted general practitioners to set their own agenda rather than react to the ideas of others. General practitioners were encouraged to think the unthinkable, and that they have done so in large numbers is the vindication of a bold policy. The BMA might now be tempted to follow this strategy in its own attempt to lead rather than follow. Practical democracy can work. ${ }^{3}$

The survey suggests that doctors want to lead normal lives, which seems to conflict with patients' expectations of them. Patients want services round the clock and easier access to them, whereas general practitioners want more free time, family life, and sleep. General practitioners are, however, willing to provide more services in the time when they are working. The obvious answer to this divergence is for multidisciplinary health care teams rather than individual doctors to be the main focus of primary health care. The teams need to share a common objective and work with local schools, housing departments, factories, churches, and societies to ensure that the community is receiving the best possible health care. The population needs to feel confident that a problem taken to any member of the health care team will be passed on to the right person. Only working from shared premises where communication is good can achieve this.

A prerequisite for such a service is a review of the salary and managerial structure of the primary health care team. Innovative, high quality service should be rewarded, perhaps by allocating the whole team a budget, to be administered by the team manager and used to purchase a range of services for the population. Incorporating all the team members into one primary health care unit, with one set of managers, could resolve the currently conflicting loyalties within the team.

As general practice moves towards a more effective, proactive service society needs to consider its use of out of 9 hours medicine. The same group of doctors that is providing an extended day time service is finding the stress of being on call too great. Deputising services may provide temporary respite but used long term they may increase out of hours requests for visits. Alternative models are possible. They include emergency primary care centres within reach of the registered population, staffed by general practitioners; mobile emergency units taking the general practitioner to the patient; or general practitioners providing primary care services in accident and emergency departments (p 735). ${ }^{\star}$ All recognise the need for the primary care health team to provide out of hours cover, but all three changes abandon the primacy of continuity of care.

Most importantly, society needs to understand that misuse of any system may destroy it. Community health councils have traditionally been the patient's watchdog; perhaps they should extend their brief to protect the health system, counselling families with high rates of use and reprimanding blatant abusers.

Also on the agenda are how we should prepare young 
doctors for general practice and how continuing education, audit, and research can be used to improve the service on offer and improve the profession's poor morale, which may be contributing to recruitment difficulties. General practice has probably the shortest period of training of all the medical specialties yet covers the broadest range of problems. Most training takes place in hospital rather than in primary care where the doctors will eventually practice. Is it time to redress the balance? Should trainees be able to spend an extra year in a training practice with greater emphasis on research and personal development?

The potential for continuing education and audit in general practice is enormous. At last general practitioners are sharing ideas about patient care and practice management, yet inadequate funding of general practice tutors keeps these two important aspects apart. If continuing education was properly funded general practice tutors could work with individual practice teams on their problems as well as with groups of health professionals at district and regional levels. This change in educational emphasis should allow the profession to review standards and consider whether it can respond to the surprisingly high number of general practitioners who would welcome re-accreditation. Until the educational emphasis shifts to addressing the needs of individual doctors and practices education will continue mainly in the unsatisfactory lecture format.

Primary care is one of the strengths of our system of health care. The health service reforms have recognised this. ${ }^{5}$ Now it is up to the profession to determine its future.

Regional Adviser in General Practice,

JACKY HAYDEN

North Western Regional Health Authority,

Manchester M60 7LP

1 Electoral Reform Ballot Services. Your choices for the future. A survey of GP opinion. UK report. London: Electoral Reform Ballot Services, 1992.

Beecham L. GPs' survey supports accreditation. BMf 1992;304:731-2.

3 Smith J. Democracy at work. BMF 1992;304:6.

4 Tonks A. Progress needed in A \& E departments. BMF 1992;304:735.

5 Secretaries of State for Health. Working for patients. London: HMSO, 1990.

\section{Vasectomy and testicular cancer}

\section{No association on current evidence}

Cancer of the testis is rare (922 registrations in England and Wales in 1985), but its incidence may be increasing. ${ }^{1-3}$ Deaths are much rarer, with a present case fatality of $10-15 \%$, and death rates are not increasing. Its age distribution is unusual for a cancer, with a peak incidence at around 25 to 29 years.

Cryptorchidism and trauma have been identified as the main risk factors, ${ }^{2+6}$ although the significance of trauma should be questioned because of possible recall bias in case-control studies and only modestly raised odds ratios. Testicular cancer has been linked with stilboestrol in utero'; little of note has emerged from occupational studies. Various hypotheses have been suggested as explanations for the increasing trend: a decade or so ago one such hypothesis was that tight trousers or underwear increased testicular temperature. Recent studies seeking explanations for the trend confirmed the main risk factors without finding an explanation for the increasing incidence. ${ }^{23}$

Vasectomy is also increasing, with more than 45000 operations performed each year in NHS hospitals and an unknown number in private clinics. ${ }^{7}$ Seeking a possible relation between vasectomy and testicular cancer therefore seems logical. Two studies, one in Ireland and one in Scotland, found some suggestion of an increased risk with relative risks of $3 \cdot 7(95 \%$ confidence interval $0 \cdot 8$ to $11 \cdot 0)$ and $4 \cdot 2(1 \cdot 8$ to $8 \cdot 2) .{ }^{89}$ The confidence intervals were wide because the rarity of the disease meant that the number of cases was small (three and eight cancers respectively). Because of the short time elapsing between operation and the diagnosis of cancer the researchers suggested investigation bias, promotion or acceleration of existing disease, and trauma as possible explanations for the associations. One English and two American case-control studies with 259, 173, and 228 testicular cancers respectively reported odds ratios of $1 \cdot 1(0.6$ to $2 \cdot 0), 0 \cdot 6(0 \cdot 3$ to $1 \cdot 2)$, and $1 \cdot 5(1 \cdot 0$ to $2 \cdot 2),{ }^{5}{ }^{11}$ but the authors of the last study considered that the marginally increased risk could be attributed to selective underreporting of vasectomy among a subset of controls.

A new cohort study from the Oxford record linkage project by Nienhuis and colleagues in this issue of the journal reports a possibly reduced risk of testicular cancer: relative risk 0.5 $(0 \cdot 1$ to $1 \cdot 4)$ (p 743). ${ }^{12}$ But, as in previous studies, because the disease is rare the numbers are small (four cancers in men with vasectomies). This type of study, linking routine health statistics, identifies an "opportunistic" cohort and lacks the rigorous follow up of a full prospective epidemiological cohort study; it is more appropriate to checking a hypothesis than to truly testing it.

The outcome is based on recorded admission to hospitals within the region, not on cancer registration. We do not know the results of histological examination or whether or to what extent selective migration, admission to hospitals for testicular cancer outside the region, undescended testis, injury, history of genitourinary disease, stilboestrol in utero, or other potential confounders might explain the possibly reduced relative risk. The authors are aware of these limitations, and some potential confounders have been exonerated by further analysis - for example, marriage ( $99 \%$ of men with vasectomy $v 75 \%$ of controls) has been shown to have little influence on the estimated relative risk.

Pooling the present estimates from both case-control and cohort studies suggests little association either way between vasectomy and testicular cancer, but this latest paper while helping to reduce concern over a possible association, may not put the issue to rest. To do so other cohorts of men who have had vasectomies should be restudied specifically for cancer of the testis; new case-control studies could be initiated. Meanwhile, the available evidence should reassure doctors and their patients that vasectomy is unlikely to increase the risk of testicular cancer.

R R WEST

Reader in Epidemiology,

Department of Epidemiology and Community Medicine,

University of Wales College of Medicine,

Cardiff CF4 4XN

\footnotetext{
1 Office of Population Censuses and Survevs. Cancer statistics: registrations, England and Wales 1985 London: HMSO, 1990.

2 Brown LM, Pottern LM, Hoover RN. Testicular cancer in young men: search for cause of epidemic increase. 7 Epidemiol Community Health 1987;41:349-54.
} 